Article

\title{
LC-MS/MS and LC-UV Determination of Moniliformin by Adding Lanthanide Ions to the Mobile Phase
}

\author{
Terenzio Bertuzzi *, Silvia Rastelli, Annalisa Mulazzi and Amedeo Pietri
}

Department of Animal Science, Food and Nutrition-DIANA, Faculty of Agriculture, Food and Environmental Sciences, Università Cattolica del Sacro Cuore, Via Emilia Parmense, 84-29122 Piacenza, Italy; silvia.rastelli@unicatt.it (S.R.); annalisa.mulazzi@unicatt.it (A.M.); amedeo.pietri@unicatt.it (A.P.)

* Correspondence: terenzio.bertuzzi@unicatt.it; Tel.: +39-0523-599262

Received: 6 September 2019; Accepted: 27 September 2019; Published: 29 September 2019

\begin{abstract}
An innovative chromatographic analysis was developed for the determination of moniliformin (MON). Because of its ionic nature, MON is weakly retained in reversed-phase chromatography and the separation may be tricky. Nevertheless, this technique is normally used either with the formation of ion pairs or employing specific RP columns for polar compounds, or combining anion exchange and hydrophobic interactions. Hydrophilic interaction chromatography (HILIC) was also used, but a non-negligible peak tailing was observed. Besides its ionic nature, MON is a di-ketone and di-ketones, mainly $\beta$-di-ketones, can easily form complexes with lanthanide ions. Then, in this work the addition of lanthanide ions to the mobile phase was investigated, aiming at improving peak shape and MON separation. $\mathrm{La}^{3+}, \mathrm{Tb}^{3+}$ or $\mathrm{Eu}^{3+}$ aqueous solutions were used as mobile phase and MON was chromatographed using a $\mathrm{LC}-\mathrm{NH}_{2}$ column. The probable formation of coordination complexes lanthanide-MON in the HPLC mobile phase allowed to obtain a symmetrical peak shape and a satisfactory chromatographic separation by both mass spectrometry (MS/MS) and UV detection. Finally, a suitable extraction and purification method for MON determination in cereal samples was developed.
\end{abstract}

Keywords: moniliformin; lanthanide complexes; LC-MS/MS; LC-UV

Key Contribution: Simple and innovative LC-MS/MS and LC-UV methods for the determination of MON were developed.

\section{Introduction}

Moniliformin (MON) is a Fusarium mycotoxin often occurring in cereals; it is mainly produced by F. avenaceum, proliferatum, subglutinans, tricinctum and verticilloides [1]. MON is a small, highly polar, acidic molecule and because of the low pKa value $(<1.7)$ of the free acid, MON occurs as a water-soluble sodium or potassium salt [2]. MON is toxic to experimental animals, causing myocardial degeneration, muscular weakness and respiratory distress [3,4]; the European Food Safety Authority (EFSA) Panel on Contaminants in the Food Chain (CONTAM) indicated haematotoxicity and cardiotoxicity as major adverse health effects of MON [5]. At present, no specific maximum levels for MON in food and feed have been set by EU legislation. MON was detected worldwide in several cereal crops at different concentration levels with values up to $2606 \mu \mathrm{g} \mathrm{kg}^{-1}$ in maize and $326 \mu \mathrm{g} \mathrm{kg}{ }^{-1}$ in wheat produced, respectively, in Italy and in the Netherlands being reported [1,6-11]. However, EFSA recommended the collection of more occurrence data on MON in foods and feeds to enable a comprehensive risk assessment for humans, and for farm and companion animals [5]. The same report recommended the development 
of validated analytical methods for MON determination. Because of its ionic nature, MON is weakly retained by reversed-phase (RP) chromatography. Nevertheless, this technique is normally used either with the formation of ion pairs [12] or employing specific RP columns for polar compounds, or combining anion exchange and hydrophobic interactions $[9,13,14]$. Hydrophilic interaction chromatography was also used, but a non-negligible peak tailing was observed [8]. In this work, a new approach was evaluated; besides its ionic nature, $\mathrm{MON}$ is a di-ketone (1-hydroxycyclobut-1-ene-3,4-dione. As seen in Figure 1, di-ketones, mainly $\beta$-di-ketones, can easily form complexes with lanthanide ions (as Lanthanum $\mathrm{La}^{3+}$, Terbium $\mathrm{Tb}^{3+}$ or Europium $\mathrm{Eu}^{3+}$ ), linking the metallic ion through the oxygen atoms [15]. Generally, three di-ketones are linked to one lanthanide ion (Figure 2).

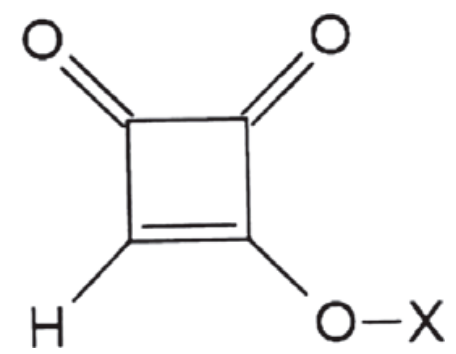

Figure 1. Chemical structure of moniliformin $(X=H, N a$ or $K)$.

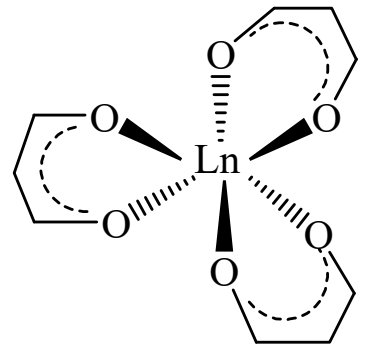

Figure 2. Structure of a $\left[\mathrm{Ln}-(\beta \text {-di-ketone })_{3}\right]$ complex (Ln: lanthanide ion).

Then, in this work the addition of lanthanide ions to the mobile phase was investigated, aiming at improving peak shape and MON separation. MON determination was carried out using both UV and mass spectrometry (MS/MS) detection. UV detection was used for its major flexibility during the development of the method and MS/MS detection for its major accuracy and lower detection limits. Finally, a suitable extraction and purification method for MON determination in cereal samples was developed.

\section{Results and Discussion}

\subsection{Development of the Chromatographic Method}

It is known that MON is weakly retained in RP chromatography, recently, specific columns for polar compounds were used for its determination. Initially, four columns were tested using an HPLC-UV instrument: an RP-8 (Lichrospher, $5 \mu \mathrm{m}$ particle size, $125 \times 4 \mathrm{~mm}$ i.d., Merck, Darmstadt, Germany), a X-Select HSS T3 (RP-18 with low ligand density, $2.5 \mu \mathrm{m}$ particle size, $100 \times 2.1 \mathrm{~mm}$ i.d., Waters Corporation, Milford, MA, USA), a XBridge BEH Amide column $(2.5 \mu \mathrm{m}$ particle size, $100 \times 2.1 \mathrm{~mm}$ i.d., Waters Corporation, Milford, MA, USA) and a Supelcosil LC-NH ${ }_{2}$ column $(250 \times 3 \mathrm{~mm}, 5 \mu \mathrm{m}$, Supelco, Bellefonte, PA, USA); a mixture acetonitrile:water $20+80 v / v$ at a flow rate of $1.0 \mathrm{~mL} \mathrm{~min}^{-1}$ was used as mobile phase. A MON standard at $1000 \mu \mathrm{g} \mathrm{L}^{-1}$ was injected; MON was weakly retained by RP-8, X-Select HSS T3 and BEH Amide columns (retention time lower than $2.0 \mathrm{~min}$ ); on the other hand, MON was strongly retained by the $\mathrm{LC}-\mathrm{NH}_{2}$ column (no peak was observed until $30 \mathrm{~min}$ ). Successively, the mobile phase was substituted with acetonitrile: $10 \mathrm{~mm} \mathrm{LaCl} 3 \cdot 7 \mathrm{H}_{2} \mathrm{O} 20+80 \mathrm{v} / \mathrm{v}$; no relevant difference 
of the retention time was observed for RP-8, X-Select HSS T3 and BEH Amide column, while MON was eluted by the $\mathrm{LC}-\mathrm{NH}_{2}$ column at $4.9 \mathrm{~min}$ (Figure 3).

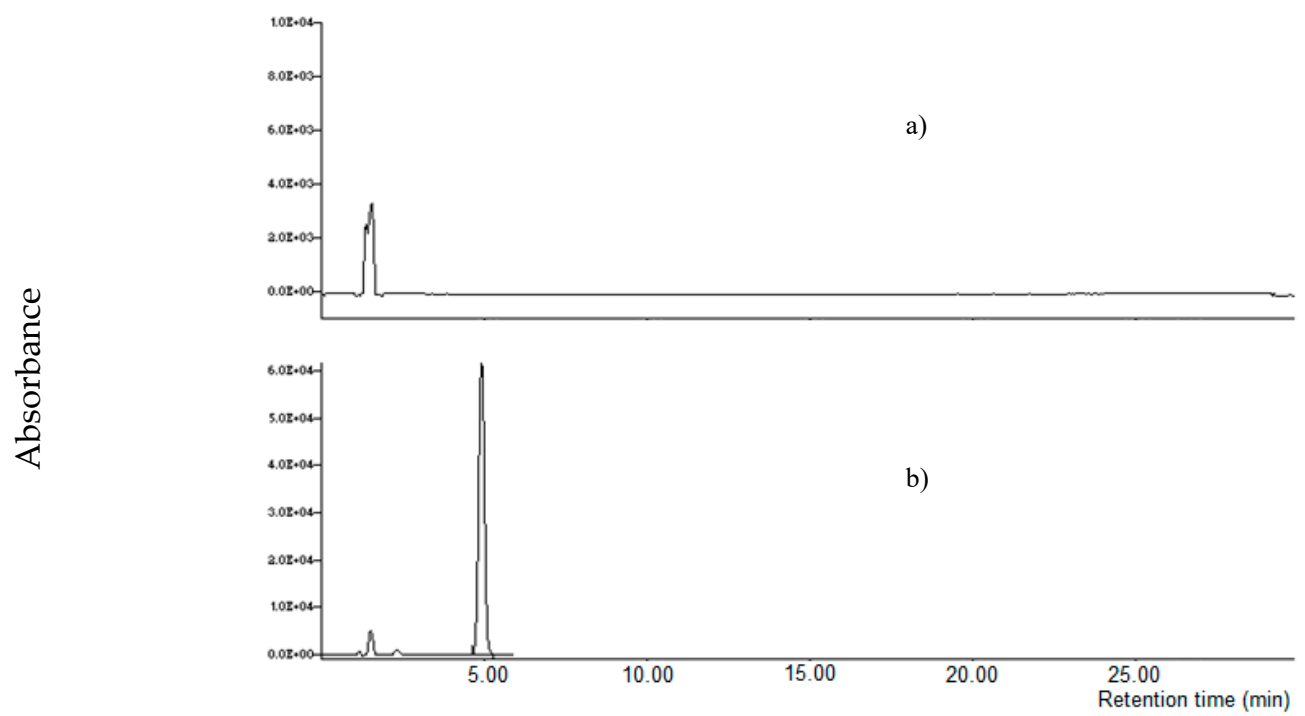

Figure 3. Chromatographic separation of moniliformin (MON) standard $\left(1000 \mu \mathrm{g} \mathrm{l}^{-1}\right)$ on a $\mathrm{LC}-\mathrm{NH}_{2}$ column using water (a) or $10 \mathrm{mM} \mathrm{La}^{3+}$ aqueous solution (b) in the mobile phase.

Five calibration standards were injected $\left(20,100,250,500\right.$ and $\left.1000 \mu \mathrm{g} \mathrm{L}^{-1}\right)$, showing a satisfactory calibration curve $\left(R^{2}=0.998\right)$. Successively, increasing concentrations from 1 to $50 \mathrm{mM}$ of $\mathrm{LaCl}_{3} \cdot 7 \mathrm{H}_{2} \mathrm{O}$ in the mobile phase were tested and a decrease of the retention time was observed (Figure 4).

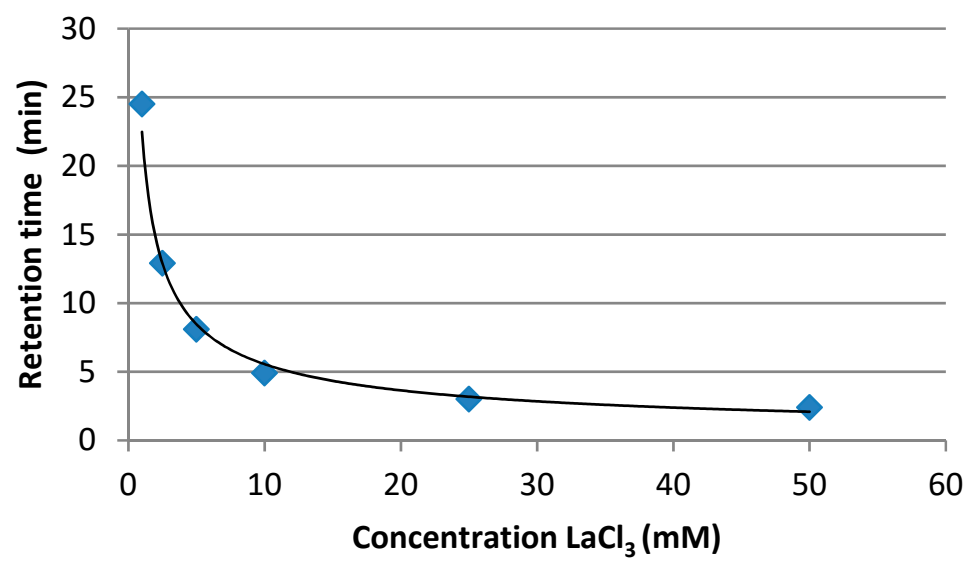

Figure 4. Variation of retention time depending on concentration of $\mathrm{LaCl}_{3}(\mathrm{mM})$ in the mobile phase.

Finally, a satisfactory chromatographic separation was obtained applying a linear gradient acetonitrile: $2.5 \mathrm{mM} \mathrm{LaCl}_{3} \cdot 7 \mathrm{H}_{2} \mathrm{O}$ (Figure 5); a low $\mathrm{LaCl}_{3} \cdot 7 \mathrm{H}_{2} \mathrm{O}$ concentration was preferred in order to delay MON elution and avoid co-elution with other substances. 


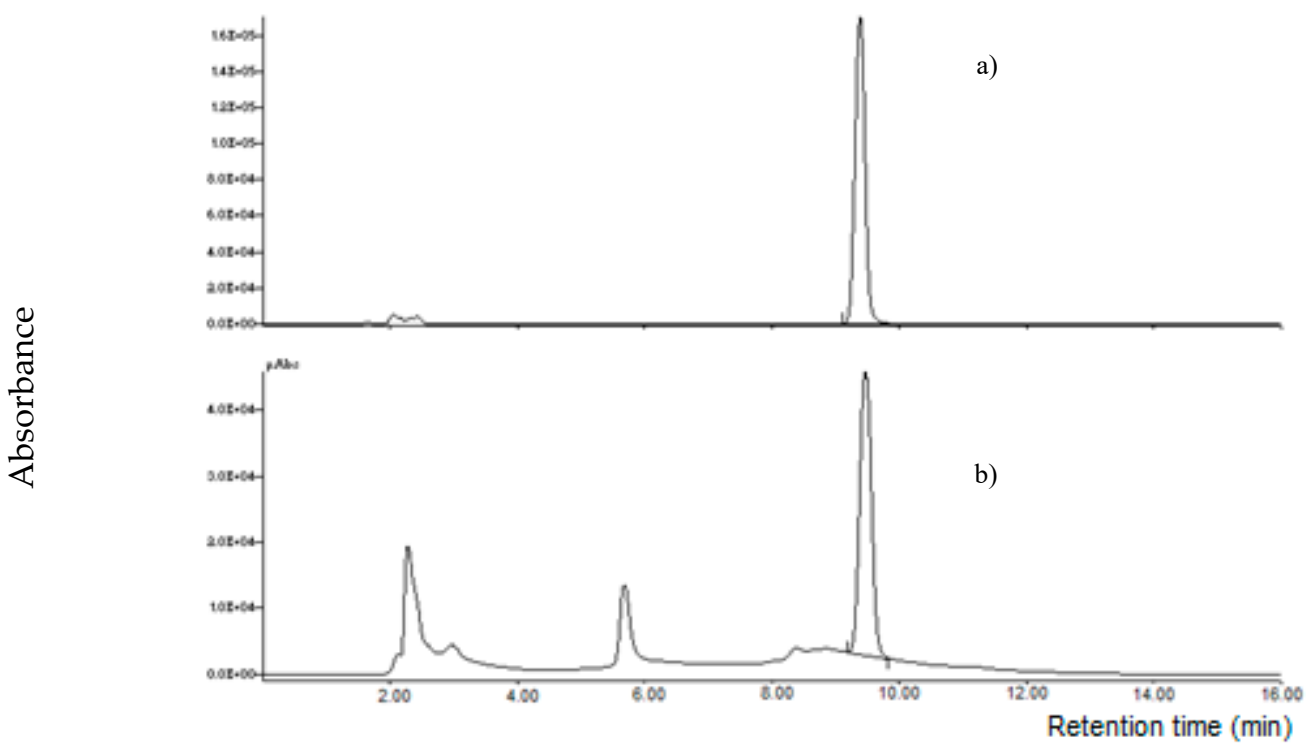

Figure 5. Chromatograms of: (a) MON standard (1000 $\left.\mu \mathrm{g} \mathrm{L}^{-1}\right)$; (b) maize spiked extract $\left(250 \mu \mathrm{g} \mathrm{L}^{-1}\right)$. Chromatographic separation was carried out using linear gradient acetonitrile: $2.5 \mathrm{mM} \mathrm{LaCl} \cdot 7 \mathrm{H}_{2} \mathrm{O}$ solution; detection at $260 \mathrm{~nm}(\mathrm{UV})$.

Similar results were obtained using $\mathrm{Tb}^{3+}$ or $\mathrm{Eu}^{3+} ; \mathrm{MON}$ was detected at a retention time of $7.0 \mathrm{~min}$ using acetonitrile: $2.5 \mathrm{mM} \mathrm{TbCl} \cdot 6 \mathrm{H}_{2} \mathrm{O} 60+40 \mathrm{v} / v$ (Figure 6). Because of its easy availability and lower cost, it was preferred to use $\mathrm{LaCl}_{3} \cdot 7 \mathrm{H}_{2} \mathrm{O}$ for the following quantitative $\mathrm{MON}$ analyses.

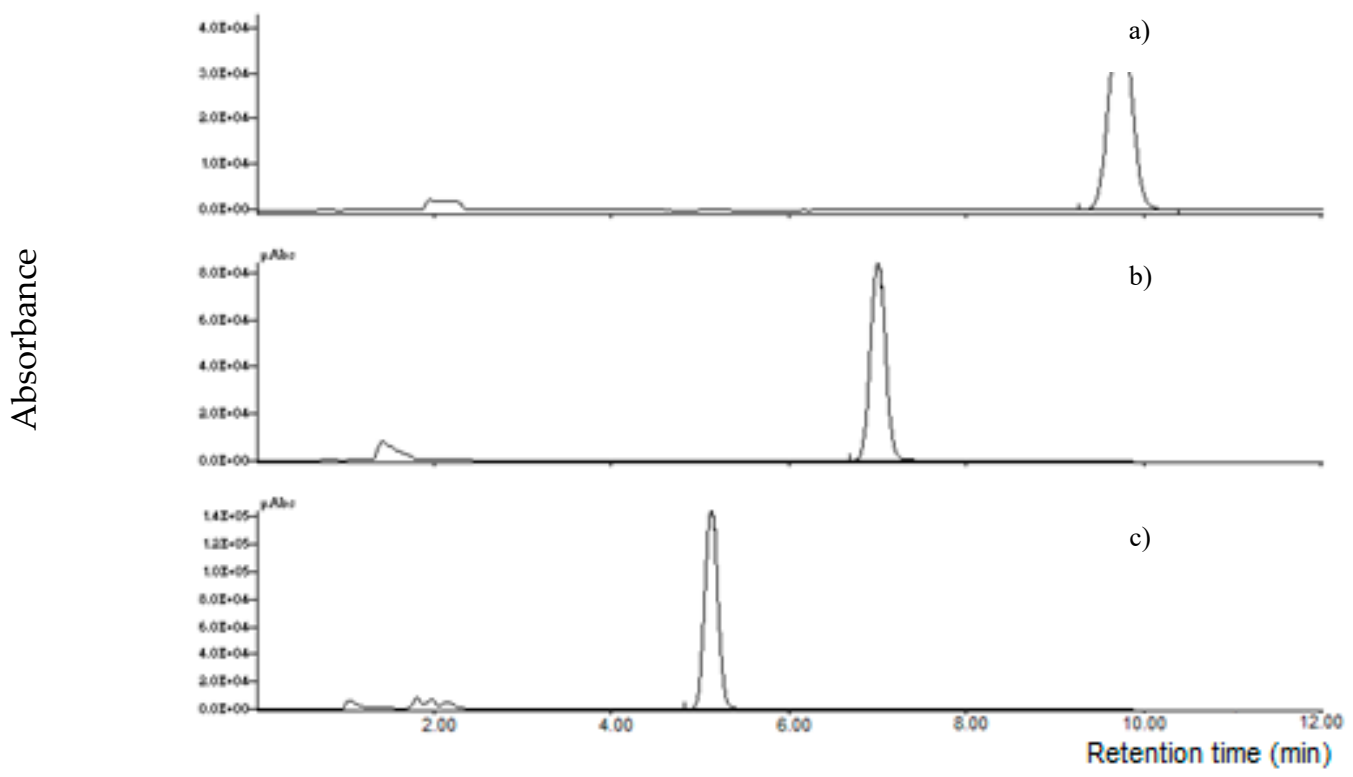

Figure 6. Chromatographic separation of MON standard $\left(1000 \mu \mathrm{g} \mathrm{L}^{-1}\right)$ on $\mathrm{LC}_{-} \mathrm{NH}_{2}$ column using: (a) $2.5 \mathrm{mM} \mathrm{Tb}^{3+}$ aqueous solution:acetonitrile $4+6 v / v$; (b) $2.5 \mathrm{mM} \mathrm{Tb}^{3+}$ aqueous solution:acetonitrile $6+4 v / v$; (c) $2.5 \mathrm{mM} \mathrm{Tb}^{3+}$ aqueous solution:acetonitrile $8+2 v / v$, as mobile phase.

The chromatograms indicate a coordination of MON with lanthanide metals during the separation, resulting in a stronger affinity of $\mathrm{MON}$ for the mobile phase and a consequent faster elution from the LC-NH$H_{2}$ column. Furthermore, increasing the concentration of $\mathrm{La}^{3+}$, a higher MON affinity for the mobile phase is favoured and therefore shorter retention times are shown. It is known that lanthanide ions can form coordination complexes with di-ketones [15], as well as with other organic compounds. 
Recently, a coordination between cyclopiazonic acid, a neurotoxin and lanthanide metals was reported by Maragos [16].

Generally, the luminescence of some lanthanides, such as Terbium and Europium, can be enhanced by interaction with selected molecules. For example, Terbium was used in post-column HPLC separation to increase the luminescence of ochratoxin A [17]. The luminescence is greatly influenced by the solvent and in particular by the presence of water, as well as by the lanthanide concentration and the chelate/lanthanide ratio [16]. Using a mobile phase $2.5 \mathrm{mM} \mathrm{Tb}^{3+}$ aqueous solution:acetonitrile $4+6 \mathrm{v} / \mathrm{v}$, we replaced the UV with a fluorimetric detector $\left(\lambda_{\mathrm{ex}}=260 \mathrm{~nm} ; \lambda_{\mathrm{em}}=550 \mathrm{~nm}\right)$ in order to evaluate a possible fluorescence. However, the results showed a negative peak at the retention time of MON detected by the fluorimeter, showing a decrease of fluorescence of the baseline (Figure 7). During the chromatographic separation, water and lanthanide concentrations are very much higher than MON concentration. These conditions do not seem to favour an increase of fluorescence, as already reported $[16,18,19]$.

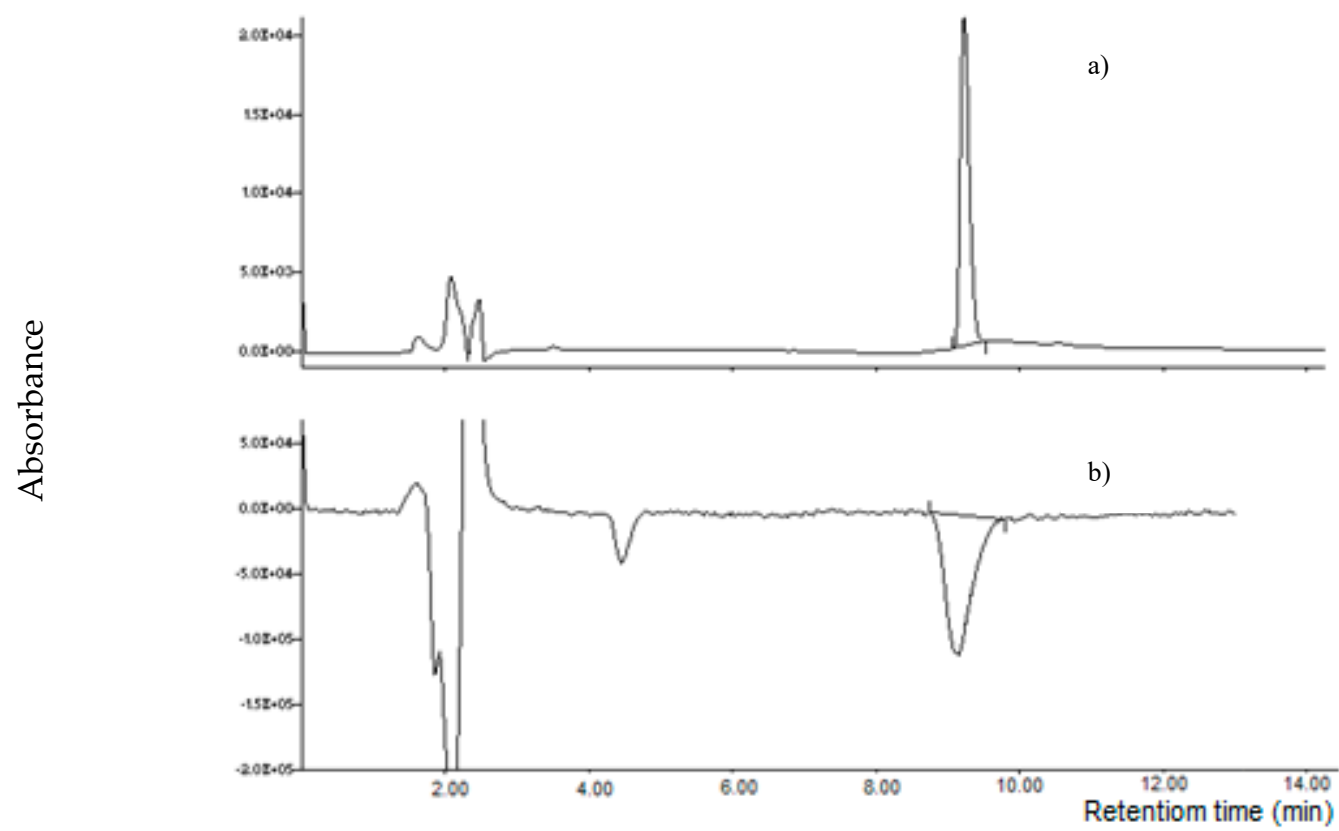

Figure 7. Chromatograms of MON standard $\left(1000 \mu \mathrm{g} \mathrm{L}^{-1}\right)$ detected by $\mathrm{UV}$ at $260 \mathrm{~nm}$ (a) and fluorimeter detector at $\lambda_{\mathrm{ex}}=260 \mathrm{~nm} ; \lambda_{\mathrm{em}}=550 \mathrm{~nm}(\mathbf{b})$.

The process of MON separation adding lanthanide ions in the mobile phase can be speculated considering the theory of ligand exchange chromatography (LEC), a chromatographic process in which complex-forming compounds are separated through the formation and breaking of labile coordinate bonds to a central metal atom, coupled with partition between a mobile and a stationary phase [20]. Based on LEC theory, the coordination of lanthanide ions with water in the mobile phase, can be partially replaced with the coordination to $\mathrm{MON}$, resulting in the formation of mixed coordination complexes (Figure 8). These coordination complexes are kinetically weak, their formation and dissociation is fast and can be described by the following reversible reaction:

$$
\mathrm{MON}+\left[\operatorname{Ln}\left(\mathrm{H}_{2} \mathrm{O}\right)_{n}\right] \leftrightarrow\left[\operatorname{Ln}(\mathrm{MON})\left(\mathrm{H}_{2} \mathrm{O}\right)_{n-1}\right]+\mathrm{H}_{2} \mathrm{O} \text { Ln-lanthanide }
$$

This process could explain the higher MON affinity for the mobile phase and the faster elution, when lanthanide concentration is increased. In absence of lanthanide ions in the mobile phase, MON is strongly retained by the stationary phase of the $\mathrm{LC}-\mathrm{NH}_{2}$ column. 
<smiles>OO[18OH]</smiles><smiles></smiles>

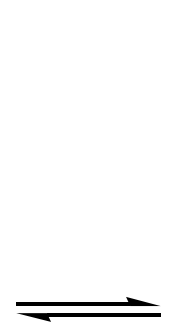

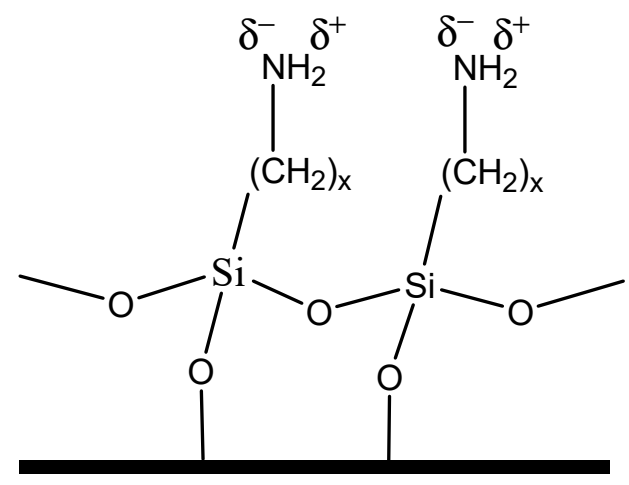<smiles></smiles>

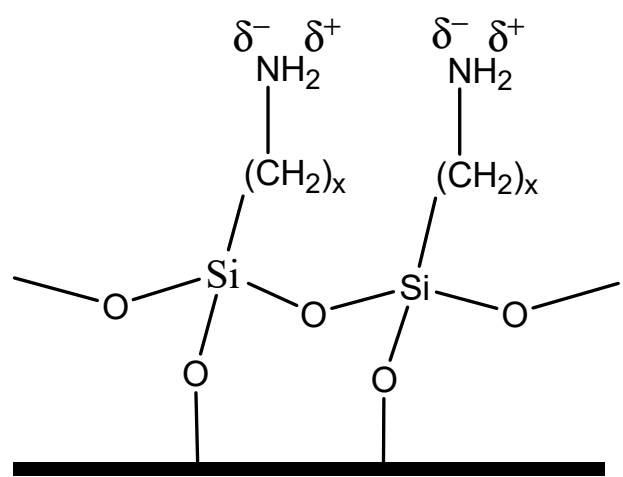

Figure 8. Possible structure of the coordination complex during chromatographic separation in presence of $\mathrm{La}^{3+}$ in the mobile phase.

Finally, the chromatographic analysis was carried out using a mass spectrometric detector (MS/MS, triple quadrupole, Thermo Fisher Scientific, San Jose, CA, USA) in order to obtain high accuracy and lower detection limits; a very low $\mathrm{LaCl}_{3} \cdot 7 \mathrm{H}_{2} \mathrm{O}$ concentration was used $(1.25 \mathrm{mM})$ to avoid troubles during the ionisation. MON was chromatographed on a $75 \times 3 \mathrm{~mm}, 3 \mu \mathrm{m} \mathrm{LC}-\mathrm{NH}_{2}$ column (Supelco) and detected at $4.4 \mathrm{~min}$, improving the limit of detection (Figure 9).

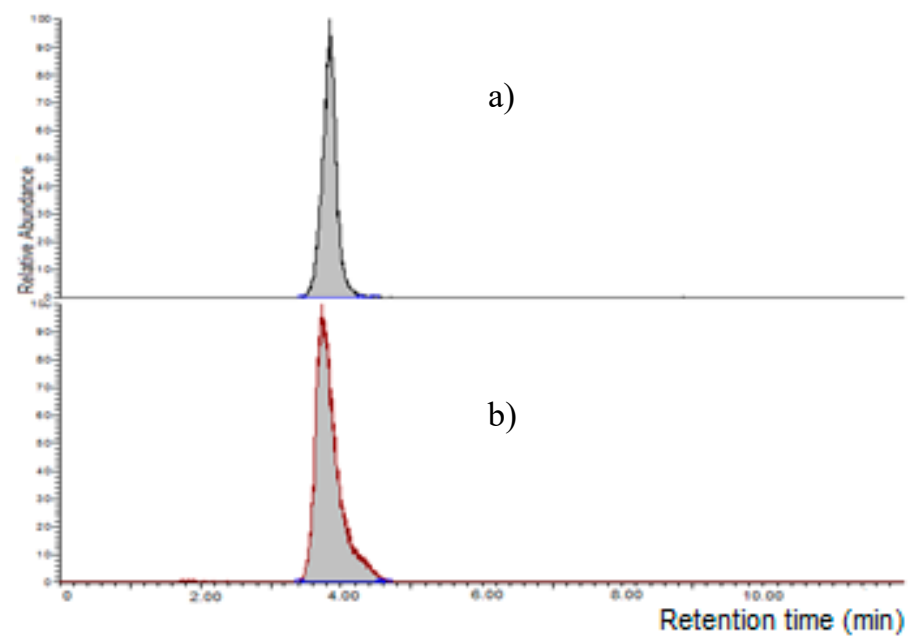

Figure 9. Chromatograms of: (a) MON standard (100 $\left.\mu \mathrm{g} \mathrm{L}^{-1}\right)$; (b) naturally contaminated maize sample $\left(1637 \mu \mathrm{g} \mathrm{kg}^{-1}\right)$. Chromatographic separation was carried out using a linear gradient methanol: $25 \mathrm{mM}$ ammonium acetate containing $1.25 \mathrm{mM} \mathrm{LaCl}_{3} \cdot 7 \mathrm{H}_{2} \mathrm{O}$; detection by MS/MS (MRM transition $m / z 97>41$ ).

\subsection{Development of an Extraction and Purification Method for Cereal Samples}

Generally, MON was extracted using a mixture acetonitrile:water 84:16 (as for tricothecenes). Considering that MON is highly water-soluble, Barthel et al. [10] and Herrera et al. [9] recently increased the percentage of water in the extraction mixture, using acetonitrile:water $50+50 v / v$ or pure 
water, obtaining higher extraction yields. Since in our tests the extract using water $100 \%$ was turbid, probably for the presence of other large polar molecules, the mixture acetonitrile:water $50+50 v / v$ was preferred. As regards the purification step, several authors used either a SAX-like SPE [9] or a MycoSep ${ }^{\circledR}$ MON 240 column [8,13]. However, Herrera et al. [10] did not obtain satisfactory recoveries using these columns and consequently no clean-up step was carried out in their method. In this work, we previously tested MycoSep ${ }^{\circledR}$ MON 240 (Romer Labs, Getzersdorf, Austria), MAX, WAX and HLB OASIS columns (Waters Corporation, Milford, MA, USA) and the Quechers procedure; in all tests, unsatisfactory purification or low recoveries were obtained. Moreover, we confirmed that the evaporation under $\mathrm{N}_{2}$ flow decreased the recovery, as reported by Herrera et al. [10]. Finally, a LC-NH column (Supelco) was tested, in order to retain MON and elute it using a lanthanide ion solution, as for the HPLC separation. This clean-up step was only introduced for HPLC-UV determination, for LC-MS/MS analysis, the presence of high concentration of $\mathrm{La}^{3+}(12.5 \mathrm{mM})$ in the purified extract worsened MON detection.

\subsection{Performances of the Method}

The result of the considered parameters are shown in Table 1. Despite the omission of clean-up step for LC-MS/MS analysis, the matrix effect, calculated at the concentration of $100 \mu \mathrm{g} \mathrm{L}^{-1}\left(800 \mu \mathrm{g} \mathrm{kg}{ }^{-1}\right.$ for a cereal sample), was low, close to $4 \%$ and $6 \%$ for wheat and maize samples, respectively.

Table 1. Validation parameters of MON analysis using UV and LC-MS/MS detector (three replicates).

\begin{tabular}{ccc}
\hline & HPLC-UV & LC-MS/MS \\
\hline $\begin{array}{c}\text { Matrix effect } \\
\left(\text { at } 800 \mu \mathrm{g} \mathrm{kg}^{-1}\right)^{*}\end{array}$ & $/$ & $\begin{array}{l}5 \% \text { (wheat) } \\
8 \% \text { (maize) }\end{array}$ \\
\hline Calibration range * $^{*}$ & $160-8000 \mu \mathrm{g} \mathrm{kg}^{-1}$ & $20-2000 \mu \mathrm{g} \mathrm{kg}^{-1}$ \\
\hline LOD $^{*}$ & $80 \mu \mathrm{gg}^{-1}$ & $10 \mu \mathrm{g} \mathrm{kg}^{-1}$ \\
\hline LOQ $^{*}$ & $200 \mu \mathrm{g} \mathrm{kg}^{-1}$ & $25 \mu \mathrm{g} \mathrm{kg}^{-1}$ \\
\hline Average recovery & & \\
Wheat & $88.2 \% \pm 5.5 \%$ & $97.1 \% \pm 4.3 \%$ \\
Maize & $84.8 \% \pm 5.4 \%$ & $96.4 \% \pm 5.1 \%$ \\
\hline LOD: limit of detection; LOQ: limit of quantification. ${ }^{*}$ Data referred to cereal sample.
\end{tabular}

A satisfactory linearity was calculated for both LC-MS/MS $\left(R^{2}=0.997\right)$ and HPLC-UV $\left(R^{2}=0.998\right)$.

The limit of detection (LOD), for a cereal sample, was 10 and $80 \mu \mathrm{g} \mathrm{kg}^{-1} \mathrm{using}$ LC-MS/MS and HPLC-UV, respectively. The decision limit $(C C \alpha)$ and the detection capability (CC $\beta)$ were 10 and $18 \mu \mathrm{g} \mathrm{kg}^{-1}$ for LC-MS/MS, 80 and $136 \mu \mathrm{g} \mathrm{kg}{ }^{-1}$ for LC-UV.

Skipping the clean-up step (LC-MS/MS analysis), the global average recoveries were $97.1 \% \pm 4.3 \%$ and $96.4 \% \pm 5.1 \%$ for wheat and maize, respectively. Using purification step (UV analysis), the average recoveries were: $86.4 \% \pm 6.4 \%$ and $89.8 \% \pm 4.5 \%$ for wheat (at 100 and $500 \mu \mathrm{g} \mathrm{kg}^{-1}$, respectively), $83.6 \% \pm 5.9 \%$ and $86.1 \% \pm 5.1 \%$ for maize (at 250 and $1000 \mu \mathrm{g} \mathrm{kg}{ }^{-1}$, respectively).

Finally, the standard deviation obtained by repeatability tests was less than $9.2 \%$.

\subsection{MON Occurrence in Cereal Samples}

MON occurred in $100 \%$ and $50 \%$ of maize and wheat samples, respectively. The levels of contamination, corrected for the recovery percentage, ranged between 38 and $3629 \mu \mathrm{g} \mathrm{kg}^{-1}$ (the last value was obtained after dilution of the sample extract) for maize (in 4 samples MON exceeded $1000 \mu \mathrm{g} \mathrm{kg}^{-1}$ ), <10 and $481 \mu \mathrm{g} \mathrm{kg}{ }^{-1}$ for wheat samples (Figure 10). 


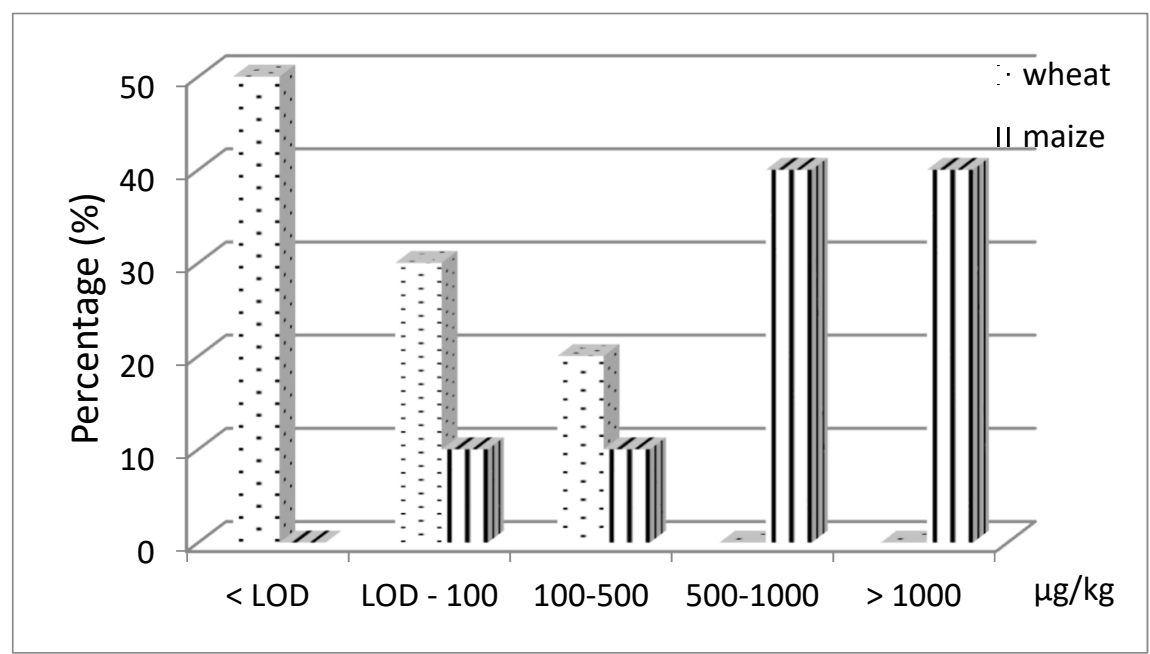

Figure 10. Frequency of occurrence $(\%)$ of MON in wheat $(n=10)$ and maize $(n=10)$ collected in northern Italy.

\section{Materials and Methods}

\subsection{Reagents and Standards}

Chemicals and solvents used for extraction and clean-up were ACS grade or equivalent (Carlo Erba, Milan, Italy); deionised water was purified through a Milli-Q treatment system (Millipore, Bedford, MA, USA). For HPLC and LC-MS/MS analysis, water, methanol and acetonitrile were HPLC grade (Merck, Darmstadt, Germany). MON (as sodium salt), Lanthanum (III) chloride heptahydrate $\left(\mathrm{LaCl}_{3} \cdot 7 \mathrm{H}_{2} \mathrm{O}\right)$, Terbium (III) chloride hexahydrate $\left(\mathrm{TbCl}_{3} \cdot 6 \mathrm{H}_{2} \mathrm{O}\right)$ and Europium (III) chloride hexahydrate $\left(\mathrm{EuCl}_{3} \cdot 6 \mathrm{H}_{2} \mathrm{O}\right)$ were obtained from Sigma-Aldrich (St. Louis, MO, USA). A MON stock standard solution was prepared in acetonitrile at a concentration of $100 \mathrm{mg} \mathrm{L}^{-1}$; working solutions were obtained by dilution using water:methanol $15+85 \mathrm{v} / \mathrm{v}$. All the solutions were stored at $-20^{\circ} \mathrm{C}$ when not in use.

\subsection{LC-MS/MS Analysis for Moniliformin Determination}

MON was extracted from cereal samples ( $10 \mathrm{~g}$ each) with $40 \mathrm{~mL}$ of a mixture acetonitrile: water $50+50 v / v$ using a rotary-shaking stirrer for $60 \mathrm{~min}$. After filtration on a folded filter paper, the extract was diluted $(1+1)$ with methanol:water $85+15 v / v$ and injected into the LC-MS/MS system $(20 \mu \mathrm{L})$. The HPLC-MS/MS system consisted of a LC 1.4 Surveyor pump (Thermo Fisher Scientific, San Jose, CA, USA), a PAL 1.3.1 sampling system (CTC Analytics AG, Zwingen, Switzerland) and a Quantum Discovery Max triple quadrupole mass spectrometer; the system was controlled by an Excalibur 1.4 software (Thermo-Fisher). MON was chromatographed on a Supelcosil LC- $\mathrm{NH}_{2}$ column $(75 \times 3 \mathrm{~mm}, 3 \mu \mathrm{m}$, Supelco, Bellefonte, PA, USA) and separated using a gradient elution with $25 \mathrm{mM}$ ammonium acetate containing $1.25 \mathrm{mM} \mathrm{LaCl}_{3} \cdot 7 \mathrm{H}_{2} \mathrm{O}$, and methanol as mobile phase $\mathrm{A}$ and $\mathrm{B}$, respectively. The gradient program was linear gradient from $15 \%$ to $35 \%$ of solvent $\mathrm{A}$ in $3 \mathrm{~min}$, then isocratic for $1 \mathrm{~min}$; column conditioning lasted $7 \mathrm{~min}$. The flow rate was $0.3 \mathrm{~mL} \mathrm{~min}{ }^{-1}$. The ionisation was carried out with an ESI interface (Thermo-Fisher) in negative mode as follows: spray capillary voltage was $3.5 \mathrm{kV}$, sheath and auxiliary gas 40 and $15 \mathrm{psi}$, respectively; skimmer $9 \mathrm{~V}$, temperature of the heated capillary $350{ }^{\circ} \mathrm{C}$. The mass spectrometric analysis was performed in selected reaction monitoring (SRM). For fragmentation of the $[\mathrm{M}-\mathrm{H}]^{-}$ion $(97 \mathrm{~m} / \mathrm{z})$, the argon collision pressure was set to $1.2 \mathrm{mTorr}$ and the collision energy to $21 \mathrm{~V}$. The detected and quantified fragment ion was $41 \mathrm{~m} / \mathrm{z}$. Quantitative determination was performed by an LC-Quan 2.0 software (Thermo-Fisher, Waltham, MA, USA). 


\subsection{HPLC-UV Analysis for Moniliformin Determination}

After extraction as for LC-MS/MS analysis, a purification step was introduced before HPLC-UV analysis; a $2 \mathrm{~mL}$ aliquot of the extract was purified through a LC- $\mathrm{NH}_{2}$ column $(500 \mathrm{mg}, 3 \mathrm{~mL}$, Supelco, Bellefonte, PA, USA), previously conditioned with $2 \mathrm{~mL}$ acetonitrile:water $50+50 \mathrm{v} / \mathrm{v}$. The column was washed with acetonitrile $(2 \mathrm{~mL})$, deionized water $(2 \mathrm{~mL})$ and $1 \mathrm{~mL}$ of a $12.5 \mathrm{mM} \mathrm{LaCl}_{3} \cdot 7 \mathrm{H}_{2} \mathrm{O}$ aqueous solution; then, MON was eluted in a graduated glass vial with additional $2 \mathrm{~mL}$ of the $12.5 \mathrm{mM}$ $\mathrm{LaCl}_{3} \cdot 7 \mathrm{H}_{2} \mathrm{O}$ aqueous solution. The purified extract was diluted $(1+1)$ using acetonitrile and injected into a HPLC-UV system $(30 \mu \mathrm{L})$. The HPLC system consisted of a Jasco PU 1580 pump (Jasco Corp., Tokyo, Japan) equipped with an AS 2055 sampling system and a UV 1575 detector set at 219 and $260 \mathrm{~nm}$. The system was governed by a Borwin 1.5 software (Jasco). MON was chromatographed on a Supelcosil LC- $\mathrm{NH}_{2}$ column $(250 \times 3 \mathrm{~mm}, 5 \mu \mathrm{m}$, Supelco $)$ and separated using a gradient elution with $2.5 \mathrm{mM} \mathrm{LaCl} 3 \cdot 7 \mathrm{H}_{2} \mathrm{O}$ (or $\mathrm{TbCl}_{3} \cdot 6 \mathrm{H}_{2} \mathrm{O}$ ) and acetonitrile as mobile phase $\mathrm{A}$ and $\mathrm{B}$, respectively. The gradient program was $15 \%$ solvent $A$ for 1 min, linear gradient to $35 \%$ solvent $A$ in $3 \mathrm{~min}$, then isocratic for $5 \mathrm{~min}$; column conditioning lasted $7 \mathrm{~min}$. The flow rate was $0.7 \mathrm{~mL} \mathrm{~min}^{-1}$; the column was thermostated at $25^{\circ} \mathrm{C}$.

\subsection{Method Validation}

For method validation, different parameters were considered. As regards LC-MS/MS, the matrix effect was examined; this effect is due to the presence of compounds that can co-elute, affecting the ionisation of the analyte. It was defined as the difference between the mass spectrometric response for the analyte in standard solution and the response for the same analyte at the same concentration in matrix extract. A comparison between the mass spectrometric response of MON in standard solution and in matrix extract at $100 \mu \mathrm{g} \mathrm{l}^{-1}$ was conducted; the matrix extract was evaluated by spiking an uncontaminated wheat or maize extract $(950 \mu \mathrm{L})$ with MON standard $(50 \mu \mathrm{L})$. Linearity of both HPLC-UV and LC-MS/MS measurement was established through five calibration standards in solvent, at concentrations between 2.5 and $250 \mu \mathrm{g} \mathrm{L}^{-1}$ for LC-MS/MS (20 and $2000 \mu \mathrm{g} \mathrm{kg}{ }^{-1}$ for a cereal sample) and between 20 and $1000 \mu \mathrm{g} \mathrm{L}^{-1}$ (160 and $8000 \mu \mathrm{g} \mathrm{kg}^{-1}$ for a cereal sample) for HPLC-UV. The limit of detection (LOD) was defined as the level corresponding to a signal-to-noise ratio $(\mathrm{S} / \mathrm{N})$ of three, while the limit of quantification (LOQ) as the lowest level for which the repeatability of the analysis was below $10 \%$. The decision limit $(C C \alpha)$ and the detection capability $(C C \beta)$ was calculated as reported by Commission Decision 2002/657/EC [21]. The accuracy of the proposed method was evaluated by determination of the recovery. Recovery experiments were performed by spiking wheat or maize flour in triplicate at two levels, 100 and $500 \mu \mathrm{g} \mathrm{kg}^{-1}$ for wheat and 250 and $1000 \mathrm{\mu g} \mathrm{kg}^{-1}$ for maize. The matrices were also analysed without spiking, as reagent blank. The spiked samples were allowed to stand for two hours at ambient temperature under a fume hood to allow any residual solvent to evaporate. Finally, the method repeatability was evaluated. Four samples ( 2 wheat and 2 maize flours) were extracted and analysed three times in different days.

\subsection{Real Sample Collection and Analysis}

A total of ten samples of maize and ten of wheat ( 2 durum wheat) were collected in northern Italy; samples were dried at $65^{\circ} \mathrm{C}$, milled using a cyclone hammer mill $(1 \mathrm{~mm}$ sieve, Pulverisette, Fritsch $\mathrm{GmbH}$, Idar-Oberstein, Germany) and homogenised. Then, an aliquot $(1 \mathrm{~kg})$ of the sample was taken and stored at $-20^{\circ} \mathrm{C}$ until the time of analysis. Quantification was carried out by LC-MS/MS, to detect lower contamination values.

\section{Conclusions}

Simple and suitable LC-MS/MS and LC-UV methods for MON determination were developed, fulfilling the wishes of the EFSA report. The simple addition of lanthanide ions to the mobile phase allowed an easy determination of MON using either mass spectrometric or UV detection. Data on 
MON occurrence in food and feed can be easily obtained using this method with a satisfactory accuracy. Further studies are needed to confirm the formation of mixed coordination complexes during the chromatographic separation. Finally, this chromatographic technique could be applied to the analysis of other mycotoxins, and also to the development of chiral separations.

Author Contributions: The manuscript was written through contributions of all authors. All authors have given approval to the final version of the manuscript. T.B., A.M. and S.R. designed the research. A.M. and S.R. performed the experiment. T.B. analyzed the data and wrote the manuscript. T.B. and A.P. supervised the research and edited and approved the final manuscript.

Funding: This research received no external funding.

Conflicts of Interest: The authors declare no conflicts of interest.

\section{References}

1. Uhlig, S.; Torp, M.; Jarp, J.; Parich, A.; Gutleb, A.C.; Krska, R. Moniliformin in Norwegian grain. Food Addit. Contam. 2004, 21, 598-606. [CrossRef] [PubMed]

2. Steyn, M.; Thiel, P.G.; Van Schalkwyk, G.C. Isolation and purification of moniliformin. J. Assoc. Off. Anal. Chem. 1978, 61, 578-580. [PubMed]

3. Kriek, N.; Marasas, W.; Steyn, P.; Van Rensburg, S.; Steyn, M. Toxicity of a moniliformin-producing strain of fusarium moniliforme var. subglutinans isolated from maize. Food Cosmet. Toxicol. 1977, 15, 579-587. [CrossRef]

4. Jestoi, M. Emerging Fusarium-Mycotoxins Fusaproliferin, Beauvericin, Enniatins, and Moniliformin-A Review. Crit. Rev. Food Sci. Nutr. 2008, 48, 21-49. [CrossRef] [PubMed]

5. EFSA Panel Contam. Risks to human and animal health related to the presence of moniliformin in food and feed. EFSA J. 2018, 16, 5082.

6. Rokka, M.; Yli-Mattila, T.; Parikka, P.; Rizzo, A.; Peltonen, K.; Jestoi, M. Presence and concentrations of theFusarium-related mycotoxins beauvericin, enniatins and moniliformin in Finnish grain samples. Food Addit. Contam. 2004, 21, 794-802.

7. Van Asselt, E.; Azambuja, W.; Moretti, A.; Kastelein, P.; De Rijk, T.; Stratakou, I.; Van Der Fels-Klerx, H. A Dutch field survey on fungal infection and mycotoxin concentrations in maize. Food Addit. Contam. Part A 2012, 29, 1556-1565. [CrossRef] [PubMed]

8. Scarpino, V.; Blandino, M.; Negre, M.; Reyneri, A.; Vanara, F. Moniliformin analysis in maize samples from North-West Italy using multifunctional clean-up columns and the LC-MS/MS detection method. Food Addit. Contam. 2013, 30, 876-884. [CrossRef] [PubMed]

9. Von Bargen, K.W.; Lohrey, L.; Cramer, B.; Humpf, H.-U. Analysis of the Fusarium mycotoxin moniliformin in cereals samples using 13C2-moniliformin and High- Resolution Mass Spectrometry. J. Agric. Food Chem. 2012, 60, 3586-3591. [CrossRef] [PubMed]

10. Herrera, M.; Van Dam, R.; Spanjer, M.; De Stoppelaar, J.; Mol, H.; De Nijs, M.; López, P. Survey of moniliformin in wheat- and corn-based products using a straightforward analytical method. Mycotoxin Res. 2017, 33, 333-341. [CrossRef]

11. Barthel, J.; Rapp, M.; Holtmannspötter, H.; Gottschalk, C. A rapid LC-MS/MS method for the determination of moniliformin and occurrence of this mycotoxin in maize products from the Bavarian market. Mycotoxin Res. 2018, 349, 9-12. [CrossRef] [PubMed]

12. Shepherd, M.J.; Gilbert, J. Method for the analysis in maize of the fusarium mycotoxin moniliformin employing ion-pairing extraction and high-performance liquid chromatography. J. Chromatogr. A 1986, 358, 415-422. [CrossRef]

13. Lim, C.W.; Lai, K.Y.; Yeo, J.F.; Tai, S.H.; Chan, S.H. Quantitative assessment of moniliformin in cereals via alternative precipitation pathways, aided by LC-LIT-MS and LC-Q-TOF-MS. Food Chem. 2015, 174, 372-379. [CrossRef] [PubMed]

14. Hallas-Møller, M.; Frisvad, J.C.; Nielsen, K.F. Production of the Fusarium Mycotoxin Moniliformin by Penicillium melanoconidium. J. Agric. Food Chem. 2016, 64, 4505-4510. [CrossRef] [PubMed] 
15. Binnemans, K. Rare-earth beta-diketonates. In Handbook of the Physics and Chemistry of Rare Earths; Gschneidner, K.A., Jr., Bünzli, J.-C.G., Pecharsky, V.K., Eds.; North Holland: Amsterdam, Holland, 2005; Volume 35, pp. 107-272.

16. Maragos, C.M. Complexation of the Mycotoxin Cyclopiazonic Acid with Lanthanides Yields Luminescent Products. Toxins 2018, 10, 285. [CrossRef] [PubMed]

17. Vazquez, B.; Fente, C.; Franco, C.; Cepeda, A.; Prognon, P.; Mahuzier, G. Simultaneous high-performance liquid chromatographic determination of ochratoxin A and citrinin in cheese by time-resolved luminescence using terbium. J. Chromatogr. A 1996, 727, 185-193. [CrossRef]

18. Armelao, L.; Quici, S.; Barigelletti, F.; Accorsi, G.; Bottaro, G.; Cavazzini, M.; Tondello, E. Design of luminescent lanthanide complexes: From molecules to highly efficient photo-emitting materials. Coord. Chem. Rev. 2010, 254, 487-505. [CrossRef]

19. Rocha, J.; Carlos, L.D.; Paz, F.A.; Ananias, D. Luminescent multifunctional lanthanides-based metal-organic frameworks. Chem. Soc. Rev. 2011, 40, 926-940. [CrossRef] [PubMed]

20. Davankov, V.A.; Navratil, J.D.; Walton, H.F. Ligand Exchange Chromatography; CRC Press: Boca Raton, FL, USA, 1988.

21. Commission Decision of 12 August 2002 implementing Council Directive 96/23/EC concerning the performance of analytical methods and the interpretation of results 2002/657/EC. Off. J. Eur. Communities 2002, L221, 8-36.

(C) 2019 by the authors. Licensee MDPI, Basel, Switzerland. This article is an open access article distributed under the terms and conditions of the Creative Commons Attribution (CC BY) license (http://creativecommons.org/licenses/by/4.0/). 